Robert B. Forbes MD FRCPC, David J. Murray MD, Mark A. Albanese PhD

\title{
Evaluation of an animal model for teaching fibreoptic tracheal intubation
}

\begin{abstract}
Twenty-seven anaesthesia faculty, fellows and revidents compared a standard intubating mannequin and an anaesthetized pig as models for teaching fibreoptic tracheal inlubation. When likened to the clinical situation, the anatomic characteristic: of the pig ainway were rated as significantly more realistic than the airway characteristics of the mannequin with the exception of the appearance of the epigiotis. In addition, the overall score for the pig model was significantly higher than the score for the mannequin and 26 of 27 evaluators rated the anaesthetized pig as the more effective teaching model. We conclude that an anaesthetized, spontaneously breathing pig is a valid model for teaching fibreoptic endotracheal intubation.
\end{abstract}

Considerable time and effort is spent teaching anaesthesia residents the skills required to maintain a patient's airway safely during surgery. In the majority of patients a secure airway can be established by direct laryngoscopy and tracheal intubation. However, if direct laryngoscopy or tracheal intubation is expected to be difficult or presents significant risk to the patient, a variety of techniques has been described to gain control of the airway, including blind nasal intubation, retrograde intubation and tracheostomy. Although useful in some patients, these techniques may be unsuccessful or associated with serious complications. ${ }^{1-9}$ In 1967 Murphy first reported the use of a fibreoptic endoscope to aid the anaesthetist when a

\section{Key words}

INTUBATION, TRACHEAL: training; ANAESTHETIC TECHNIQUES: fibreoptic laryngoscopy; EDUCATION: residents.

From the Department of Anesthesia and Office of Consultation and Research in Medical Education, University of lowa College of Medicine, lowa City, Iowa

Prcsented at the 1987 Canadian Anaesthetists' Society Annual Meeting, Calgary, Alberta, June 1987.

Address correspondence to: Dr. R.B. Forbes, Department of Anesthesia, University of Iowa, Iowa City, Iowa $\mathbf{5 2 2 4 2}$ difficult intubation is encountered ${ }^{10}$ Since then fibreoptic tracheal intubation has become a valuable technique for establishing a secure airway in a variety of difficult clinical situations. ${ }^{11-20}$

Despite its usefulness, fibreoptic endoscopy has not enjoyed widespread use among anaesthetists. ${ }^{15,21}$ Many perceive the fibreoptic laryngoscope to be a relatively complicated instrument that requires special care and expertise. Insufficient instruction, as well as infrequent opportunity to apply the technique, may also contribute to the problem of underutilization. Often, training in fibreoptic intubation consists only of a brief explanation of the technique just before an anaesthetist's first attempt at fibreoptic intubation in the clinical setting. This commonly occurs when a patient with a difficult airway presents for an urgent surgical procedure. With the operating room staff waiting to begin the procedure, an anaesthetist's initial attempt at fibreoptic intubation is certainly stressful, often prolonged, and frequently unsuccessful. These circumstances discourage future use of the technique when it is indicated.

Experience with laryngoscopy and intubation of the pig in the laboratory suggested that the airway anatomy of the pig may be sufficiently comparable with that of a human to provide a realistic model for teaching physicians the technique of fibreoptic tracheal intubation. The purpose of this study, therefore, was to assess the validity of using a spontaneously breathing, anaesthetized pig as a teaching model for fibreoptic tracheal intubation and to compare it with a standard intubating mannequin.

\section{Methods}

Faculty anaesthetists, anaesthetic fellows and residents assessed fibreoptic laryngoscopy and intubation of a pig and a standard intubating mannequin. Following the intubation, each anaesthetist voluntarily rated both models for clinical realism.

In the pig model anaesthesia was induced and maintained by inhalation of halothane and oxygen. The animal was placed in the supine position, intravenous access established and ECG and body temperature monitored. End-tidal $\mathrm{CO}_{2}$ and halothane concentrations were moni- 
tored using mass spectrometry. A transtracheal block using lidocaine was performed. Spontaneous ventilation was maintained through an oropharyngeal airway or a tracheostomy connected to a semi-closed carbon dioxide absorber system. After a stable level of anaesthesia had been established members of the Department of Anesthesia performed both orotracheal and nasotracheal fibreoptic laryngoscopy and intubation of the pig.

Following evaluation of the pig model, an intubating mannequin was also evaluated using both nasal and oral fibreoptic laryngoscopy and intubation. In both models an Olympus LF-l fibreoptic intubating laryngoscope was used to complete the procedures

Immediately following intubation of the models each participant completed a questionnaire assessing the animal model and the mannequin by assigning a score to eight specific characteristics including the presence of secretions, appearance of the tongue, the epiglottis and the vocal cords, the position of the larynx, the effect of respiration, the appearance of the trachea and the general technique of fibreoptic laryngoscopy. Each of the characteristics was scored using a four-point scale with $1=$ poor, $2=$ fair, $3=$ good, $4=$ excellent and $U A=$ unable to assess. The participants were then asked to assign an overall score evaluating each model as an aid to instruction in fibreoptic tracheal intubation. Finally each participant was asked, "For anaesthesiologists or other physicians learning the technique of fibreoptic tracheal intubation which model would be more effective?"

For each characteristic evaluated, the means for the two models were statistically analyzed using a test for related samples with $P<0.05$ considered significant.

\section{Results}

Twenty-seven members of the Department of Anesthesia assessed each model. Fifteen participants were faculty members, three were fellows and nine were residents. Five individuals had no previous experience with fibreoptic intubation, 14 had performed less than ten intubations, five had performed ten to 25 intubations and three had performed more than 25 intubations using a fibreoptic endoscope.

Assessments of the anatomical characteristics of the pig and the mannequin are shown in Table I. Scores for the pig model were significantly higher for all characteristics with the exception of the appearance of the epiglottis when compared with the intubating mannequin.

In addition, the overall score for the pig model, as an aid to instruction in fibreoptic endotracheal intubation, was significantly higher than the rating for the mannequin (Table 1I). Twenty-six of the 27 evaluators rated the pig as the more effective model for providing a realistic prac-
TABLE I Comparison of airway characteristics of the pig and mannequin, as models to simulate clinical fibreoptic endotracheat intubation (mean $\pm \mathrm{SE}$ )

\begin{tabular}{lll}
\hline Character & Pig & Mannequin \\
\hline Presence of secretions & $3.00 \pm 0.15 \dagger$ & $1.04 \pm 0.04$ \\
Anatomy of tongue & $2.56 \pm 0.12 \dagger$ & $1.52 \pm 0.12$ \\
Appearance of cpiglottis & $2.50 \pm 0.19$ & $2.15 \pm 0.15$ \\
Position of larynx & $3.07 \pm 0.14 \dagger$ & $2.16 \pm 0.16$ \\
Appearance of cords & $3.00 \pm 0.15^{*}$ & $2.35 \pm 0.18$ \\
Effect of respiration & $3.27 \pm 0.13 \dagger$ & $1.09 \pm 0.06$ \\
Appearance of trachea & $3.23 \pm 0.16 \dagger$ & $1.64 \pm 0.14$ \\
Technique of fibreoptic intubation & $3.67 \pm 0.09 \dagger$ & $1.85 \pm 0.14$ \\
\hline
\end{tabular}

Related sample t test.

$* P<0.05$.

$+\mathrm{P}<0.001$

TABLE II Frequency distribution and means of ratings of overall effectiveness as a leaming experience for each model

\begin{tabular}{|c|c|c|c|c|c|}
\hline Scores & $\begin{array}{l}I= \\
\text { poor }\end{array}$ & $\begin{array}{l}2= \\
\text { fair }\end{array}$ & $\begin{array}{l}3= \\
\text { good }\end{array}$ & $\begin{array}{l}4= \\
\text { excellent }\end{array}$ & Mean \\
\hline Pigr model & 0 & 1 & 8 & 17 & $3.62^{*}$ \\
\hline Mannequin & 6 & 18 & 2 & 0 & 1.85 \\
\hline
\end{tabular}

Related sample $\mathbf{t}$ test. $* \mathrm{P}<0.05$.

tice opportunity to physicians leaming the technique of fibreoptic tracheal intubation.

\section{Discussion}

As the indications for fibreoptic endoscopy become wider, both in the operating room and in the intensive care unit, ${ }^{10-20}$ it is becoming increasingly important for physicians to be adequately trained in the technique. A standard method for teaching clinical skills has been described as "see one, do one, teach one." However, in a complicated skill involving considerable eye-hand coordination this approach to clinical teaching may be far from ideal. In addition, learning a complex technical skill, such as fibreoptic intubation, during the course of patient care presents several problems. The patient may experience unnecessary discomfort or be at risk of injury if the procedure is not successfully completed. Operating time may be lost as the novice struggles to master a new skill, and operating room personnel frequently become impatient with the resulting delay. This type of atmosphere makes learning difficult.

Intubation of a mannequin may be a useful teaching aid. However, it does not represent a realistic clinical experience. ${ }^{22-24}$ In addition to the pig several other animal species were considered for evaluation as intubation models but each presented significant practical problems. ${ }^{27}$ Intubation of the dog is relatively easy and 
does not adequately challenge the student to develop the skills necessary to perform fibreoptic tracheal intubation of a difficult airway. Sheep also are not an effective model for fibreoptic intubation because apnoea occurs at a level of anaesthesia that leaves the laryngeal and swallowing reflexes intact. Also, in sheep as in other ruminants, vomiting or regurgitation of gastric contents is common during induction of anaesthesia or instrumentation of the airway. Anaesthetized cats have been shown to be a realistic and effective model for tracheal intubation, ${ }^{25,26}$ but because of their small size cats are not an appropriate model for fibreoptic intubation.

The pig was chosen as the model for this project because intubation in this species is difficult. ${ }^{27,28}$ The mouth is long, narrow and does not open widely. The larynx is small and there is a ventral angulation into the trachea. In addition, although pigs rarely vomit, they are susceptible to laryngospasm and the presence of pharyngeal diverticula make recognition of the anatomy challenging. Therefore, successful intubation of the pig requires recognition of the anatomic landmarks; overcoming obstacles, such as excessive salivation or laryngospasm; and manipulation of the fibreoptic laryngoscope through the larynx of a spontaneously breathing animal before advancing the tracheal tube into position. This very closely resembles the clinical situation.

Use of an anaesthetized pig as an intubating model allows the student sufficient time to develop the skills required for successful fibreoptic tracheal intubation. By working in a non-stressful environment during the learning process residents quickly develop confidence in their ability to control and manipulate the fibreoptic laryngoscope before attempting the technique on a patient in the operating room. We conclude that an anaesthetized, spontaneously breathing pig is a valid model for teaching fibreoptic tracheal intubation.

\section{References}

1 Butler FS, Cirillo AA. Retrograde tracheal intubation. Anesth Analg 1960; 39: 333-8.

2 Giuffrida JG, Bizzarri $D V$, Latteri $F S$, Berger $H C$, Schmookler A, Fierro FE. Prevention of major airway complications during anesthesia by intubation of the conscious patient. Anesth Analg 1960; 39: 201-11.

3 Waters DJ. Guided blind endotracheal intubation. Anaesthesia 1963; 18: 158-62.

4 Singh A. Blind nasal intubation. Anaesthesia 1966; 21: $400-2$.

5 Thomas $J L$. Awake intubation. Anaesthesia 1969; 24: $28-35$.

6 Pedersen B. Blind nasotracheal intubation. Acta Anaesthesiol Scandinay 1971; 15: 107-24.

7 Bourke D, Levesque PR. Modification of retrograde guide for endotracheal intubation. Anesth Analg 1974; 53: $1013-4$.

8 Kopman $A F$, Wollman $S B$, Ross $K$, Surks $S N$. Awake endotracheal intubation: A review of 267 cases. Anesth Analg $1975 ; 54: 323-7$.

9 McIntyre JWR. The difficult tracheal intubation. Can J Anaesth 1987; 34: 204-13.

10 Murphy $P$. A fibre-optic endoscope used for nasal intubation. Anaesthesia 1967;22: 489-91

11 Keenan MA, Stiles $C M$, Kaufman RL. Acquired laryngeal deviation associated with cervical spine disease in erosive polyarticular arthritis. Anesthesiology 1983; 58: 441-9.

12 Sinclair $J R$, Mason RA. Ankylosing spondylitis. Anaesthesia $1984 ; 39: 3-11$.

13 Watson $C B$, Bowe EA, Burk W. One-lung anesthesia for pediatric thoracic surgery: a new use for the fiberoptic bronchoscope. Anesthesiology 1982; 56: 314-5.

14 Alfrey DD, Ward CF, Harwood IR, Mannino FL. Airway management for a neonate with congenital fusion of the jaws. Anesthesiology 1979; 51: 340-2.

15 Stiles $C M$. A flexible fiberoptic bronchoscope for endotracheal intubation of infants. Anesth Analg 1974; 53 : $1017-9$.

16 Ovassapian A, Dykes MHM, Yelich SJ. Difficult pediatric intubation - an indication for the fiberoptic bronchoscope. Anesthesiology 1982; 56: 412-3.

17 Rosenbaum SH, Rosenbaum LM, Cole RP, Askanazi J, Hyman AI. Use of the flexible fiberoptic bronchoscope to change endotracheal tubes in critically ill patients. Anesthesiology 1981; 54: 169-70.

18 Shinnick JP, Freedman AP. Bronchofiberscopic placement of a double-lumen endotracheal tube. Crit Care Med 1982; 10: 544-5.

19 Shulman MS, Levesque PR. Fibrcoptic bronchoscopy for tracheal and endobronchial intubation with a doublelumen tube. Can J Anaesth 1987; 34: 172-3.

20 Ovassapian A, Land P, Schafer MF, Cerullo L, Zalkind $M S$. Anesthetic management for surgical corrections of severe flexion deformity of the cervical spine. Anesthesiology 1983 ; 58 : 370-2.

21 Latto IP. Management of difficult intubation. In: Difficulties in tracheal intubation. Latto IP, Rosen M (ed). London. Baillière Tindall, 1985: pp. 99-106.

22 Howells TH, Emery FM, Twentyman JEC. Endotracheal intubation training using a simulator. $\mathrm{Br} J$ Anaesth 1973; 45: 400-2.

23 Ovassapian A, Dykes MHM, Golmon ME. A training programme for fibreoptic nasotracheal intubation. Use of model and live patients. Anaesthesia 1983; 38: 795-8.

24 Ovassapian A, Yelich SJ, Dykes MHM, Brunner EE. Fiberoptic nasotracheal intubation - incidence and causes of failure. Anesth Analg 1983; 62: 692-5. 
25 Sankaran $K$, Yadlapolli J, Zakhary G. Evaluation of a tcaching method for endotracheal intubation in neonates. Annals RCPSC 1985; 18: 135-6.

26 Mehta MP, Albanese MA, Murray DJ, Chow FC. Evaluation of an animal simulation to teach endotracheal intubation. Proceedings of the Association of American Medical Colleges 1986; 24: 14-7.

27 Jennings $S$. General anesthesia of ruminants and swine. In: Textbook of Veterinary Anesthesia. Soma LR (Ed). Baltimore, Williams and Wilkins Company, 1971: pp. 350-8.

28 Rowson LEA. Endotracheal intubation of the pig. Veterinary Record 1965; 77: 1465.

\section{Résumé}

Vingt-sept patrons et résidents en anesthésie ont comparé l'intubation endotrachéale par fibroscope utilisant un mannequin standard et un porc anesthésté. A l'exception de l'apparence de l'épiglotte, les caractéristiques anatomiques des voies aériennes du porc se rapprochaient plus de la situation clinique que celles du mannequin. En plus, des intubations réussies avec le porc étaient significativement supérieures qu'avec le mannequin et 26 des 27 évaluateurs ont caractérisé l'inubation chez le porc anesthésié plus efficace pour l'enseignement. On conclut qu'un porc anesthésié, respirant spontanément est un modele valable pour l'enseignement de l'inubation endotrachéale par fibroscope. 